\title{
Production and Characterization of Indium Oxide and Indium Nitride
}

\author{
Luis C. Jimenez B., Henry A. Méndez P., Beynor A. Páez S., María E. Ramírez O., Hernán Rodríguez H. \\ Grupo de Películas Delgadas, Depto. de Física \\ Pontificia Universidad Javeriana, Bogota D.C., Colombia
}

Received on 8 December, 2006

\begin{abstract}
Thin films of indium oxide $200 \mathrm{~nm}$ thick and indium nitride $150 \mathrm{~nm}$ thick were produced by reactive sputtering deposition onto soda lime substrates. The Indium cathode was kept under vacuum attached to a high voltage dc. The $\operatorname{In}_{x} \mathrm{O}_{y}$ films were obtained in argon-oxygen mixture with total pressure between 2 and $7 \mathrm{~Pa}$, current density between 0.04 and $0.56 \mathrm{~mA} / \mathrm{cm}^{2}$ and substrate temperature of $300 \mathrm{~K}$. The $\operatorname{In}_{x} \mathrm{~N}_{y}$ films were obtained in argon-nitrogen mixture with total pressure between 1 and $5 \mathrm{~Pa}$, current density between 0.18 and $14 \mathrm{~mA} / \mathrm{cm}^{2}$ and substrate temperature of $320 \mathrm{~K}$. Results revealed that thin films give rise to high conductivity, are transparent and have a carrier density of $10^{19} \mathrm{~cm}^{-3}$ for $\operatorname{In}_{x} \mathrm{O}_{y}$ and $10^{17} \mathrm{~cm}^{-3}$ for $\operatorname{In}_{x} \mathrm{~N}_{y}$. These results were obtained mainly from temperature dependent $\alpha$ and $\sigma$ measurements. The reduced chemical potential was calculated considering three different scattering mechanisms i.e. interaction with optically polarized phonons, interaction with ionized impurities and interaction with grains, in order to identify the main scattering mechanism, which resulted to be due to impurities.
\end{abstract}

Keywords: Indium oxide; Indium nitride; Scattering mechanisms; Thermoelectric power

\section{INTRODUCTION}

A research program on production and characterization of semiconductor oxides with high conductivity and high transmittance in the IR near region as required for optoelectronic devices is being carried out. Semiconducting oxides namely, $\mathrm{ZnO}, \mathrm{SnO}_{2}, \mathrm{SnO}_{2}: \mathrm{F}$, and particularly InO thin films prepared by DC reactive sputtering show high conductivity and high transmittance in the near IR region. Because of these characteristics and other important properties, InO thin films are suitable for technological applications where high transparency in the visible region and high conductivity are required [1], [2], [3]. Indium oxide is a wide-band-gap semiconductor $(\sim 3.7$ $\mathrm{eV}$ ), which exhibits an isolating behavior in the stoichiometric form $\mathrm{In}_{2} \mathrm{O}_{3}$. Nevertheless, when it is prepared in an oxygendeficiency way, it can reach a high n-type doping level due to the intrinsic defects such as oxygen vacancies. $\operatorname{In}_{x} \mathrm{~N}_{y}$ thin films possess interesting properties such as high conductivity and transmittance in the visible and near IR regions. Due to this special property amongst others, great attention has been put to the study of optical and electrical properties aimed to their use in technological applications. [4], [5].

\section{EXPERIMENTAL}

Reactive sputtering of indium was carried out at a pressure of $2.8 \mathrm{~Pa}$. The base pressure inside the chamber was $5 \mathrm{mPa}$, and the average cathode-anode voltage was $2.2 \mathrm{kV}$. $\operatorname{In}_{x} \mathrm{O}_{y}$ thin films were grown on well-cleaned soda lime substrates in a pure atmosphere of $\mathrm{O}_{2} / \mathrm{Ar}$, $(\mathrm{PO} / \mathrm{PAr}=0.09)$. More details about the reactor can be found elsewhere. [6]. Reactive sputtering of indium was carried out in $\mathrm{Ar} / \mathrm{N}_{2}$ at a pressure of 2.6 $\mathrm{Pa}$. The cathode-anode average voltage was $1.8 \mathrm{kV} . \operatorname{In}_{x} \mathrm{~N}_{y}$ thin films were grown on well-cleaned soda lime substrates in a pure atmosphere of $\mathrm{N}_{2} / \mathrm{Ar}(\mathrm{PN} / \mathrm{PAr}=0.3)$.

The films were investigated by means of experimental mea- surements of transmittance (400 to $1000 \mathrm{~nm}$ ), dc electrical conductivity $\sigma$, Hall Effect and thermoelectric power $(\alpha)$ in order to determine the electrical transport properties. The thermoelectric power and electrical conductivity measurements were carried out in vacuum, using equipment as that shown in Fig. 1. The description of the assembly can be found elsewhere [7]. The growth conditions (current density, anodecathode potential, substrate temperature) as well as the gas mixture were systematically changed until the best compromises between transparency and conductivity were obtained.

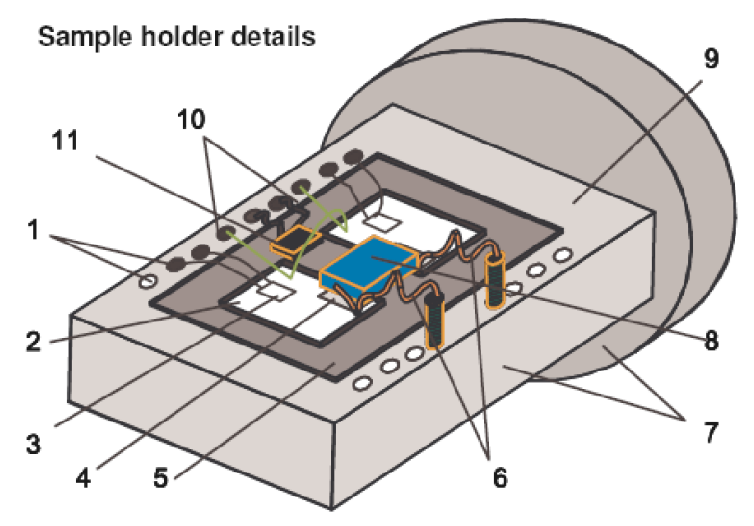

1. Hole trough. 2. Isolating sheet. 3 . Heating resistor. 4. Conducting sheet. 5. Ceramics. 6. Thermovoltage probe. 7. Copper. 8. Sampled fixed with silver paint. 9. Sample holder. 10. Differential thermocouple. 11. Thermocouple.

FIG. 1: Thermoelectric power equipment. 


\section{RESULTS AND DISCUSSION}

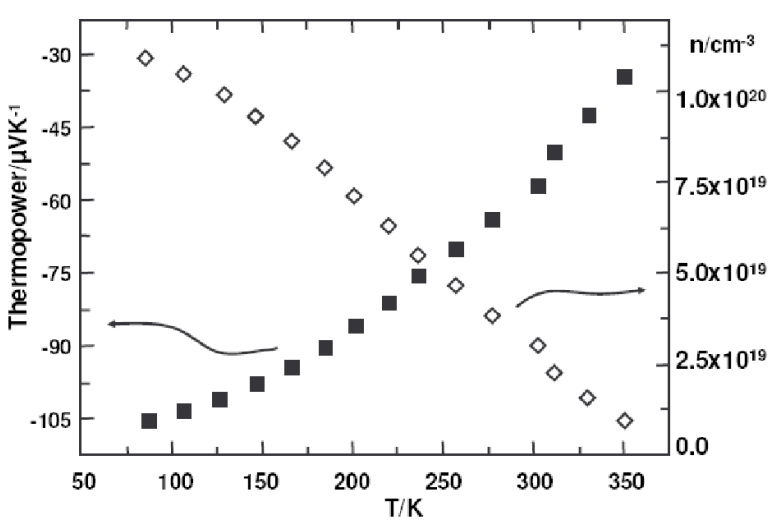

FIG. 2: Thermoelectric power measurements and carrier density in $\mathrm{In}_{x} \mathrm{O}_{y}$ grown by reactive DC sputtering.

Typical curves of carrier density and thermoelectric power measurements versus temperature in $\operatorname{In}_{x} \mathrm{O}_{y}$ thin films are shown in Fig. 2, and were used to calculate the reduced chemical potential. Both curves have been plotted together for a better comparison. A particular sample grown at a pressure of $2.7 \mathrm{~Pa}$ and in an $\mathrm{O}_{2} / \mathrm{Ar}(\mathrm{PO} / \mathrm{PAr}=0.09)$ atmosphere, with an anode-cathode potential of $2.2 \mathrm{kV}$, and current density of 0.7 $\mathrm{mA} / \mathrm{cm}^{2}$, revealed the best quality and therefore was selected out of the sample set grown under different conditions. Additionally, transmittance values were $86 \%$, which were determined in the $[350 \mathrm{~nm}, 1000 \mathrm{~nm}]$ region corresponding to the far UV and near IR regions. The values of the thermoelectric power correspond to degenerated semiconductors [8] and the theoretical expression after solving the Boltzmann equation is given by [8]

$$
\alpha=-\frac{k}{e}\left[-\eta+\frac{(r+5 / 2) F_{r+3 / 2}(\eta)}{(r+3 / 2) F_{r+1 / 2}(\eta)}\right]
$$

being $\mathrm{k}$ the Boltzmann constant, e the charge-electron magnitude, $\eta$ the reduced chemical potential, $F$ is Fermi's integral and $r$ a quantity which involves the scattering mechanisms i.e. Interaction with optically polarized phonons $(r=1 / 2)$, interaction with ionized impurities $(\mathrm{r}=-1 / 2)$ and interaction with grains $(r=3 / 2)$. [9]:

Fermi's integral for this sort of semiconductors is given by

$$
F_{r}(\eta)=\eta^{r+1}\left(1+\frac{\pi^{2}}{8 \eta^{2}}+\ldots\right)
$$

in this case the thermoelectric power yields to

$$
\alpha=-\frac{k}{e}\left[\frac{\pi^{2}}{3}(r+3 / 2) \eta^{-1}\right]
$$

The advantage of equation (3) is that the chemical potential can be readily evaluated thus allowing the carrier concentration, $\mathrm{n}$, to be found. Figure 3 shows the dependence of the reduced chemical potential on temperature for all the three scattering mechanisms mentioned above. The importance of this calculation is based on the clear-cut differences among the three different scattering mechanisms that the charge carriers can likely suffer under the transport process.

Figure 3 show reduced chemical potential in $\operatorname{In}_{x} \mathrm{O}_{y}$ thin films grown by DC reactive sputtering, taking into account three different scattering mechanisms: interaction with optically polarized phonons $(r=1 / 2)$, interaction with ionized impurities $(r=-1 / 2)$, and interaction with grains $(r=3 / 2)$.

The main scattering mechanism with $\operatorname{In}_{x} \mathrm{O}_{y}$ thin films is due to impurities. The other two are not considered, since for a high doping level the charge carrier-phonon interaction becomes weaker due to the induced intrinsic defects, as it has been proved by other techniques [10]. The grain potential is not high enough to induce a main effect in the charge carrier transport because the net charge density per charge can easily overpass the barrier potential on the grain boundaries [1].

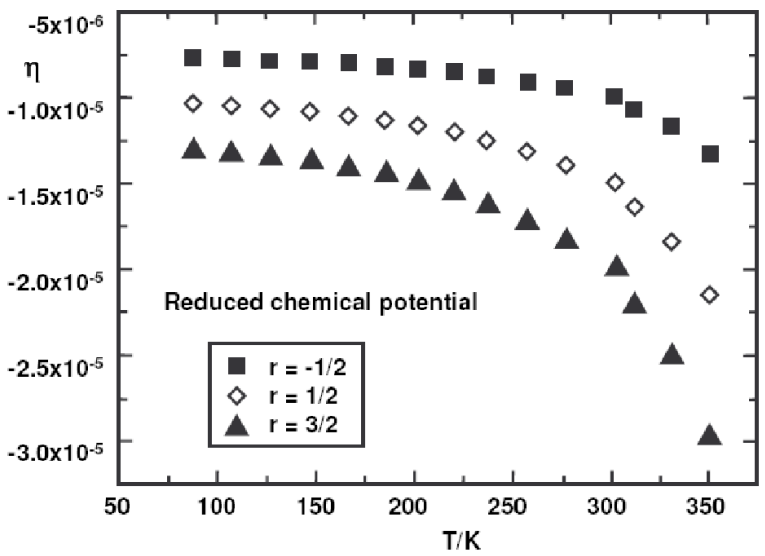

FIG. 3: The temperature dependence of reduced chemical potential of $\operatorname{In}_{x} \mathrm{O}_{y}$.

Figure 4 shows the temperature-dependent behavior of the electrical conductivity measurements and mobility. Mobility was evaluated by means of the relation $\sigma=\operatorname{en} \mu$. Mobility values are strongly affected by changes in temperature. This means that despite having a main scattering mechanism in all the measurement range, changes in mobility can be due to changes in carrier concentration as it can be seen in Fig. 2, since for low concentrations the mean free path is higher than for high concentrations, supporting the argument that the main scattering mechanism in $\operatorname{In}_{x} \mathrm{O}_{y}$ thin films prepared by DC reactive sputtering is due to impurities.

The typical curve of thermoelectric power measurements against temperature in $\operatorname{In}_{x} \mathrm{~N}_{y}$ thin films is shown in Figure 5 . A particular sample grown at a pressure of $2.8 \mathrm{~Pa}$, in an $\mathrm{O}_{2} / \mathrm{Ar}$ $(\mathrm{PN} / \mathrm{PAr}=0.3)$ atmosphere, with an anode-cathode potential of $2.2 \mathrm{kV}$, and current density of $14 \mathrm{~mA} / \mathrm{cm}^{2}$, showed the best quality and therefore was selected out of the sample set grown 


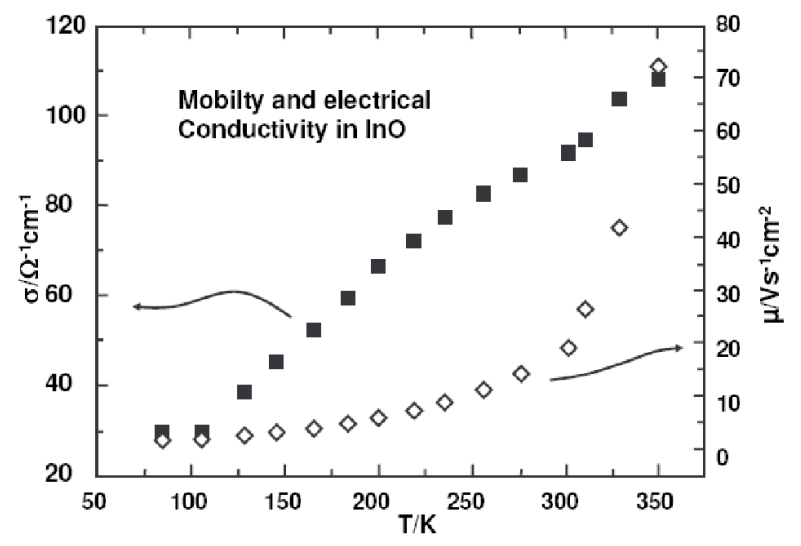

FIG. 4: Mobility and electrical conductivity of $\operatorname{In}_{x} \mathrm{O}_{y}$ thin films prepared by DC reactive sputtering.

under different conditions. Additionally, transmittance values were $92 \%$, which were determined in the [350 nm, 1000 $\mathrm{nm}]$ region and correspond to the far UV and near IR regions. The values of the thermoelectric power correspond to non degenerated semiconductors and the theoretical expression after solving the Boltzmann equation is given by equation (1).

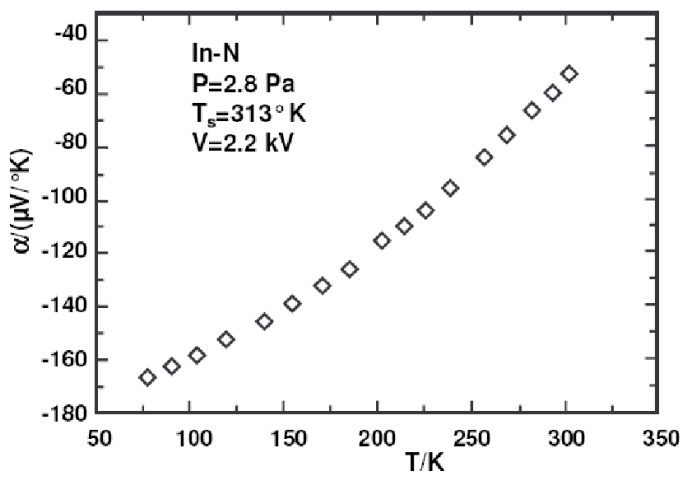

FIG. 5: Temperature-dependent variation curve of the $\alpha$ obtained with a sample of $\operatorname{In}_{x} \mathrm{~N}_{y}$ deposited by reactive pulverization at a pressure of $2.8 \mathrm{~Pa}$.

Figure 6 shows the behavior of the temperature-dependent electrical conductivity measurements. From thermoelectric power $\alpha$ and conductivity $\sigma$ measurements, a carrier density of $10^{17} \mathrm{~cm}^{-3}$ for $\operatorname{In}_{x} \mathrm{~N}_{y}$, with $\mathrm{m}^{*}=0.3 \mathrm{~m}_{o}, \mathrm{r}=1 / 2$, was obtained in order to identify the main scattering mechanism, which was due to an interaction between free carriers and ionized impurities.

Figure 7 shows temperature-dependent behavior of concentration $\mathrm{n}$ and mobility $\mu$. Mobility was evaluated by means of the relation $\sigma=\mathrm{en} \mu$. The $\mathrm{n}$ grows and $\mu$ decreases. They are approximately constant for temperatures more than 200 $\mathrm{K}$, possibly, since when increasing temperature, the density of free carriers as result of increase in the density of ionized impurities $\mathrm{N}_{I}$ is increased and saturation of the ionization of impurities appears for temperatures more than $200 \mathrm{~K}$. This one

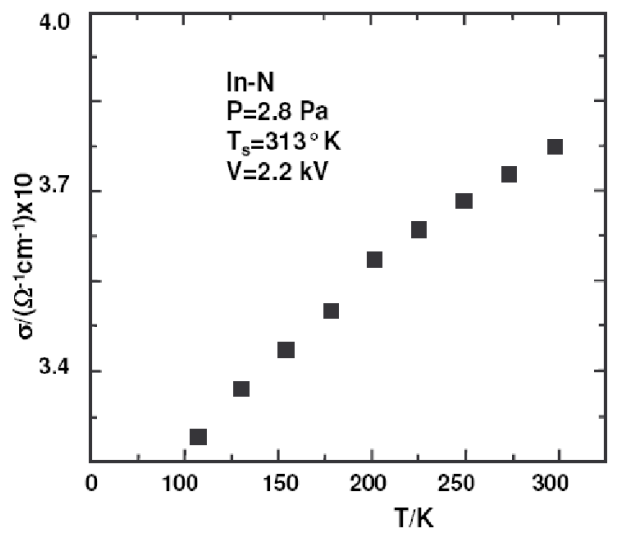

FIG. 6: Temperature-dependent variation of the electrical conductivity $\sigma$ of InN.

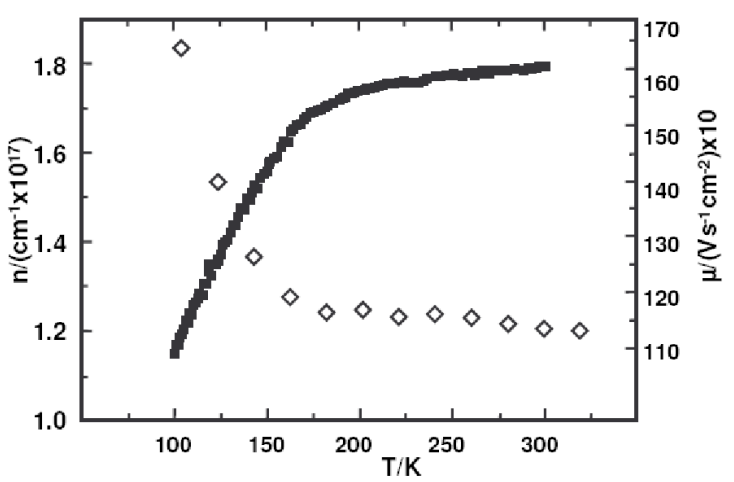

FIG. 7: Temperature-dependent variation of carrier mobility and density.

leads to saturation in the density of free carrier. The reduction of $\mu$ could be by the increase $\mathrm{N}_{I}$ in when the mechanics of dominant scattering are ionized impurities.

\section{CONCLUSION}

$\operatorname{In}_{x} \mathrm{O}_{y}$ thin films prepared by $\mathrm{DC}$ reactive sputtering reveal suitable electrical and optical characteristics when grown at a pressure of $2.8 \mathrm{~Pa}$ and in an $\mathrm{O}_{2} / \mathrm{Ar}$ atmosphere with an anode-cathode potential of $2.2 \mathrm{kV}$ and current density of 0.7 $\mathrm{mA} / \mathrm{cm}^{2}$. Transmittance values were $86 \%$, which were determined in the $[350 \mathrm{~nm}, 1000 \mathrm{~nm}]$ region corresponding to the far UV and near IR regions. A carrier density in the order of $10^{19} \mathrm{~cm}^{-3}$ was determined from the thermoelectric power measurements, indicating that $\operatorname{In}_{x} \mathrm{O}_{y}$ thin films grown under the established conditions are degenerated. Additionally, it was found from calculations of the reduced chemical potential that the main scattering mechanism is that due to impurities. It was determined that for high temperatures the mobility is high, what basically means that mobility values are well mediated by carrier concentration.

$\mathrm{In}_{x} \mathrm{~N}_{y}$ thin films prepared by DC reactive sputtering possess 
suitable electrical and optical characteristics when grown at a pressure of 2.6 $\mathrm{Pa}$ and in an $\mathrm{N}_{2} / \mathrm{Ar}$ atmosphere with an anodecathode potential of $2 \mathrm{kV}$ and current density of $14 \mathrm{~mA} / \mathrm{cm}^{2}$. Transmittance values were $92 \%$. A carrier density in the order of $10^{17} \mathrm{~cm}^{-3}$ was determined from thermoelectric power measurements, indicating that they are non degenerated semiconductors. It was found from calculations of the reduced chemical potential that the main scattering mechanism is that due to ionized impurities.

We report a simple method to produce conductive, transparent foils. The films are non-stoichiometric and their good conductivity and transmittance may be explained by the relatively large crystallite size. The main scattering mechanism is due to impurities. We describe promising findings for further research on the optoelectronics material fields.
[1] M. Bender, N. Katsarakis, E. Gagaoudakis, E. Hourdakis, E. Douloufakis, V. Cimalla, and G. Kiriakidis, J. Appl. Phys. 90 (10), 5382 (2001).

[2] Giuseppe Faraci, Agata R. Pennisi, and Rosaria Puglisi, Phys. Rev. B 65, 024101 (2002).

[3] M. V. Golubkov, and G. É. Tsydynzhapov, JETP Letters 71 (12), 516 (2000).

[4] S. Chang, Chemical Sensors, Kondansha, Tokyo, 1983, p.78

[5] R. Lalauze, P. Breuil, and C. Pijolat, Sensors Actuators B. 3, 175 (1991)

[6] L. C. Jiménez, H. Méndez and B. A. Páez. Rev. Col. Fís. 32, 63
(2000).

[7] B. A. Páez, H. Méndez, and L. C. Jiménez, Rev. Col. Fís. 32, 537 (2002)

[8] G. Gordillo, B. A. Páez, C. E. Jácome, and J. M. Flórez. (1999) TSF342, (160-166).

[9] G. C. Jain and W. Berry, Transport Properties of Solids and Solid State Solar Energy Conversion, (Ed. Tata, Mc Graw Hill, N. Delhi, 1972).

[10] Muneaki Hase, Kunie Ishioka, Kiminori Ushida, Masahiro Kitajima. Annihilation of Int. Conf. Phys. 